
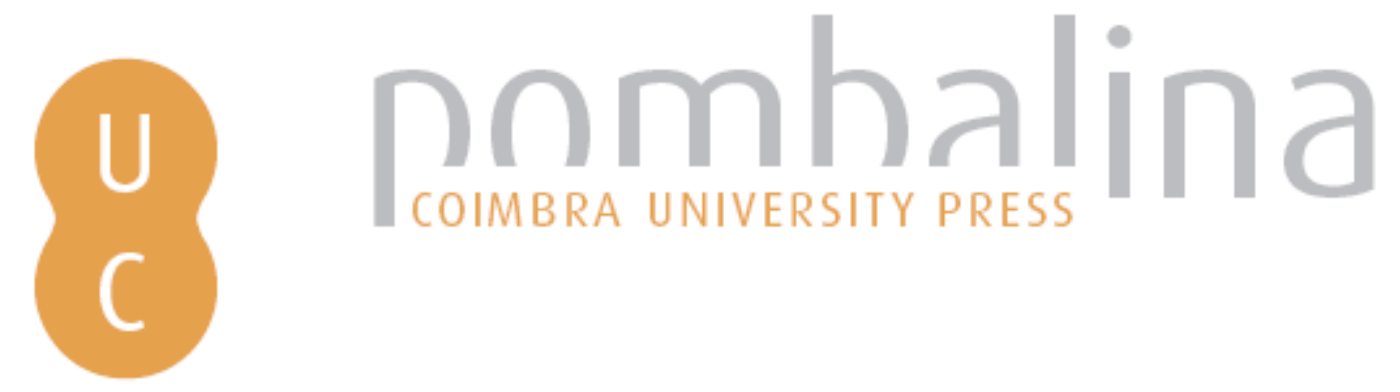

\title{
O sistema alimentar da cidade do Rio de Janeiro no século XVIII: as cerâmicas destinadas ao processamento e estocagem de alimentos
}
Autor(es):
Souza, Marcos André Torres de; Lima, Tania Andrade
Publicado por: Imprensa da Universidade de Coimbra
URL
persistente:
URI:http://hdl.handle.net/10316.2/45255
DOI:
DOI:https://doi.org/10.14195/978-989-26-1720-6_15
Accessed : $\quad$ 26-Apr-2023 11:12:40

A navegação consulta e descarregamento dos títulos inseridos nas Bibliotecas Digitais UC Digitalis, UC Pombalina e UC Impactum, pressupõem a aceitação plena e sem reservas dos Termos e Condições de Uso destas Bibliotecas Digitais, disponíveis em https://digitalis.uc.pt/pt-pt/termos.

Conforme exposto nos referidos Termos e Condições de Uso, o descarregamento de títulos de acesso restrito requer uma licença válida de autorização devendo o utilizador aceder ao(s) documento(s) a partir de um endereço de IP da instituição detentora da supramencionada licença.

Ao utilizador é apenas permitido o descarregamento para uso pessoal, pelo que o emprego do(s) título(s) descarregado(s) para outro fim, designadamente comercial, carece de autorização do respetivo autor ou editor da obra.

Na medida em que todas as obras da UC Digitalis se encontram protegidas pelo Código do Direito de Autor e Direitos Conexos e demais legislação aplicável, toda a cópia, parcial ou total, deste documento, nos casos em que é legalmente admitida, deverá conter ou fazer-se acompanhar por este aviso.

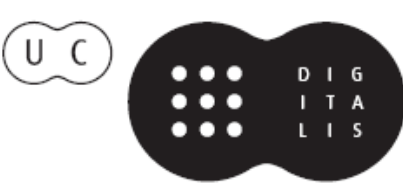


Carmen Soares

\section{Cilene da Silva Gomes Ribeiro}

\section{(coords.)}

MESAS

\section{ALIMENTAÇÃ O, SAÚDE \& CULTURA}

\section{IU LUO-BRASILEIRAS}

\section{VOLUME II}

IMPRENSA DA UNIVERSIDADE DE COIMBRA

COIMBRA UNIVERSITY PRESS

PUCPRESS 


\title{
O Sistema Alimentar da CidAde do Rio de Janeiro no século XVIII
}

\author{
(The food system in $18^{\text {th }}$ century \\ Rio de Janeiro)
}

\section{I. As CerÂmicas destinadas ho Processamento E ESTOCAGEM DE ALIMENTOS}

\section{(Earthenware used to process and storage food)}

\author{
Marcos André Torres de Souza \\ Museu Nacional / Universidade Federal do Rio de Janeiro \\ TORRESDESOUZA@YAHOO.cOM \\ Tania Andrade Lima \\ Museu Nacional / Universidade Federal do Rio de Janeiro \\ TALIMA8@GMAIL.COM
}

Resumo: Este artigo apresenta um exame preliminar dos artefatos cerâmicos encontrados na Rua da Assembleia, centro do Rio de Janeiro, onde foi identificada uma grande área de deposição arqueológica referente ao fim do século XVII e início do século XVIII. Apresenta também algumas considerações iniciais sobre os significados desses artefatos e sua relação com diferentes grupos de pessoas. Argumentamos que essa amostra associa-se, muito possivelmente, a práticas culturais bastante diversas e associadas à emergência do Rio de Janeiro como um centro urbano de importância no universo colonial português.

Palavras-Chave: arqueologia urbana, Rio de Janeiro colonial, cerâmica histórica, multiculturalismo, inovação cultural.

Авstract: This article presents a preliminary examination of the low fired earthenwares found in Assembléia street, Rio de Janeiro downtown, where a large archaeological trash area dated from late 17th century and early 18th century was found. It also presents some considerations on the meanings attached to these artifacts, and their relation with different groups of people. We argue that this sample represents a possible evidence of disparate cultural practices that are connected with the emergence of Rio de Janeiro as an important city in the portuguese colonial world. KeYwORDs: urban archaeology, colonial Rio de Janeiro, historical low-fired earthewares, multiculturalism, cultural innovation. 
Com o início da colonização do Brasil, grupos muito distintos entre si e provenientes de regiões separadas por grandes distâncias geográficas foram postos em contato. Esses encontros tiveram consequências profundas na formação social brasileira, influenciando de forma decisiva a conformação da nossa sociedade. A cerâmica encontrada no sítio arqueológico da Rua da Assembleia constitui uma evidência pujante desse processo, sugerindo um quadro complexo e muito rico de negociações e fusões, realizadas por diferentes sujeitos.

Acreditamos que por meio do exame da materialidade desses encontros temos condições de flagrar os modos pelos quais, nas práticas cotidianas - e em particular, na constituição das práticas alimentares -, diferenças foram negociadas entre os agentes envolvidos e relações inteiramente novas foram construídas. Tendo isso em mente, apresentamos algumas evidências e reflexões iniciais que julgamos estar associadas a essas trocas. Nossa ênfase recai nas evidências que acreditamos estar relacionadas à presença portuguesa na cidade.

A amostra contemplada compreende as cerâmicas simples, por nós entendidas como aquelas que foram queimadas em baixas temperaturas e não receberam qualquer tipo de vitrificação, glasura ou esmalte. Ficamos restritos aqui às cerâmicas de uso cotidiano e que foram utilizadas no processamento, transporte, armazenagem e consumo de alimentos. Essa amostra está representada por um número mínimo de 550 peças, referentes a 469 recipientes e 81 tampas. A quantificação e análise dos recipientes foi baseada na estimativa do número mínimo de peças, realizada a partir das bases e bordas.

\section{A amostra cerâmicA}

Uma parte significativa da amostra (50\% do total) é composta por uma cerâmica empregada no preparo de alimentos, de produção local ou regional. Simples, feita geralmente com argilas grosseiras e muito plásticas, comumente enriquecidas com temperos e queimadas em baixas temperaturas, ela não recebeu qualquer tipo de glasura, esmalte ou vitrificação. Esses recipientes apresentam geralmente marcas de contato com o fogo, superfícies externas escuras e marcas de fuligem em diferentes pontos. Esse perfil sugere a presença de grupos domésticos vivendo na parte central da cidade, nas imediações do local dos achados. Sua relevância no conjunto material do sítio se equipara a sua importância na vida cotidiana das pessoas, tendo em vista que eles foram utilizados sobretudo no processamento de alimentos.

É interessante notar que as características físicas dessas panelas apresentam peculiaridades locais que diferem, ao menos em alguns aspectos, do que vem sendo encontrado em outras regiões brasileiras no mesmo período. E o caso da sua técnica de manufatura, já que elas foram feitas em sua maioria por 
moldagem da parte inferior, enquanto em outras regiões a técnica empregada foi predominantemente a do roletado. Uma evidência de adoção da técnica do moldado são marcas horizontais visíveis, resultantes da junção entre a parte moldada e o acabamento da parte superior da peça, feito por modelagem.

Os traços definidores dessa cerâmica emergiram em um contexto de grande pluralidade étnica e cultural. Enquanto o Rio de Janeiro crescia e se tornava, gradualmente, uma cidade cosmopolita, sua população se diversificava. Com isso, os encontros entre pessoas muito diferentes entre si passaram a fazer parte do seu cotidiano. Produzida por e para pessoas que viviam na cidade, essa cerâmica é um indicador muito sensível do ritmo e intensidade desses encontros, e uma variedade de influências culturais podem ser mapeadas nela.

Como era de se esperar em um contexto brasileiro setecentista, podem ser identificados nesses objetos muitos referenciais culturais africanos. A população escravizada nas áreas urbanas se ocupava de uma grande variedade de atividades, aí incluídos o trabalho nas cozinhas e a produção de itens manufaturados localmente, entre eles, a cerâmica ${ }^{1}$. Desta forma, eram os cativos que ocupavam os espaços de produção e uso dos recipientes cerâmicos de uso culinário. Ainda que sujeitos à ingerência dos proprietários, estavam em posição de negociar a adoção de elementos próprios na definição da sua forma, decoração e uso. Uma das evidências mais significativas da sua penetração no universo material analisado vem do tipo de panela mais popular da amostra: de forma globular, contorno simples, borda direta, base plana muito pequena e duas asas localizadas no bojo superior da peça (Figura 1).

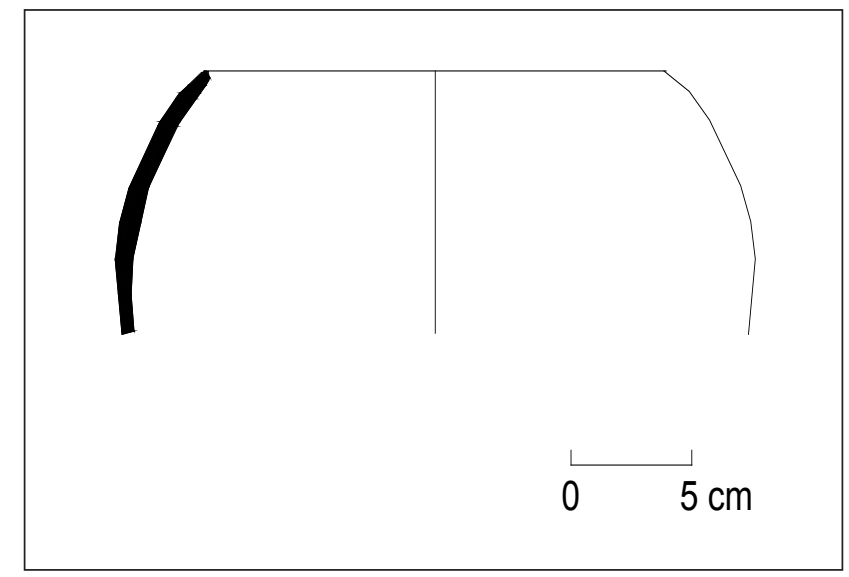

Figura 1: Recipiente de forma globular

Desenho: Marcos André Torres de Souza.

$1 \quad$ Mott 1976; Agostini 2010. 
A forma globular era comumente usada pelos grupos que viviam na África Central, região de onde veio a grande maioria dos cativos que viviam então no Rio de Janeiro ${ }^{2}$. Embora influenciada por referenciais desses grupos, essa panela esteve sujeita a um tipo de negociação prudente. A introdução de bases planas e asas, atributos incomuns nas mais diversas regiões africanas associadas ao tráfico atlântico, permitia um manuseio mais fácil do recipiente, e provavelmente foi decorrente de demandas da sociedade colonial. Dessa forma, combinavam-se nesses recipientes elementos africanos e outros resultantes de necessidades locais vinculadas aos colonizadores.

Apenas alguns deles possuíam decoração. Quando presente, ela ocupava o bojo superior, formando faixas contínuas que circundavam a peça. Os motivos decorativos eram, na maioria das vezes, produzidos apenas com os dedos e as unhas, dispensando qualquer tipo de ferramenta e compondo ungulados, digitados e digitungulados ${ }^{3}$. Além desses motivos, encontramos alguns poucos fragmentos com incisões ou ponteados executados com o auxílio de ferramentas.

As decorações feitas nesses recipientes eram discretas, pouco visíveis, de grande simplicidade e pouquíssimo apuro técnico. Esse perfil fornece pistas importantes acerca das estratégias empregadas pelos cativos visando a expressão de referenciais próprios. A sua adoção sugere que eles usaram como expediente a sutileza. A despeito da introdução prudente e quase silenciosa dessas decorações, elas podem ter funcionado como um mecanismo de identificação e diferenciação. Considerando essas evidências, entendemos que nas análises futuras dessa amostra é importante considerar a imbricação desses recipientes com relações de poder e com a criação de novos referenciais étnicos com as populações envolvidas, o que pode representar uma relevante via de análise.

Uma outra importante categoria funcional da amostra, que apresentou uma frequência surpreendentemente alta (37,9\% da amostra), está associada à estocagem e ao transporte de alimentos líquidos e sólidos. É composta por recipientes grandes, os mais frequentes com paredes e bordas extrovertidas, muito semelhantes entre si, cuja forma se repete sistematicamente, com algumas variações (Figura 2). Eles não apresentam evidências de contato com o fogo - o que permite descartar seu uso para fins culinários - e possuem, muitas vezes, marcas de uso nas suas paredes internas, que apresentam vestígios variados de abrasão e desgaste, sugerindo a estocagem de diferentes tipos de gêneros, tanto sólidos quanto líquidos. Sua manufatura foi feita maciçamente por meio de torno, diferindo, nesse aspecto, dos demais. Assim como nos outros conjuntos, apresentou como tempero quartzo moído. Todavia, quando comparados às peças

Cavalcanti 2005.

Acerca dessas e outras técnicas aqui descritas, ver Chmyz 1976. 
usadas no preparo de alimentos, esse mineral mostrou uma ligeira tendência a apresentar partículas menores e mais homogêneas. A queima também mostrou diferenças sutis, predominando uma assinatura de cor clara.

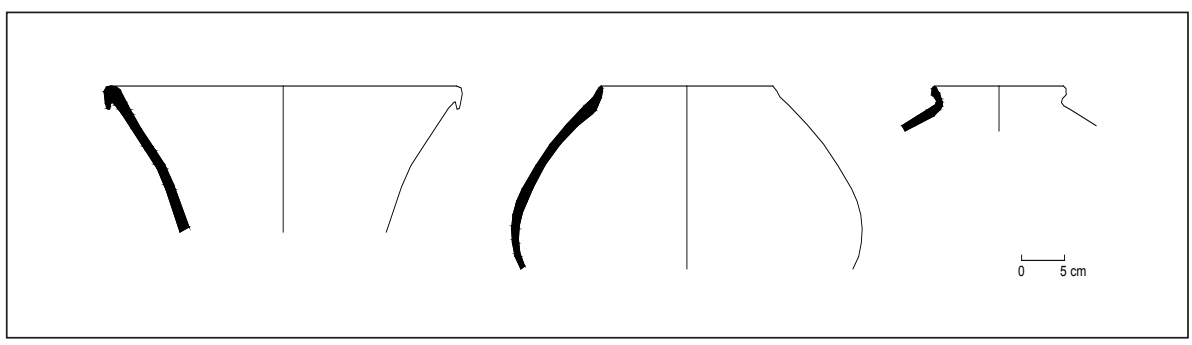

Figura 2: Recipientes usados na estocagem e transporte de alimentos Desenho: Marcos André Torres de Souza.

A recorrência e a elevada frequência dessa forma permite aventar a possibilidade de ter existido nas imediações do local dos achados um estabelecimento de secos e molhados. Essa possibilidade é reforçada por um grupo muito particular de pequenos recipientes, de diferentes dimensões, mas sempre com a relação altura/largura muito baixa. Eles apresentam uma asa típica, formada pela junção de uma tira de argila que, presa ao seu corpo, facilitava o manuseio da peça (Figuras 3 e 4). No bojo de algumas delas, há números feitos por incisão, junto à borda. Marcas similares foram encontradas na escavação de um poço seiscentista no Vale de Alcântara, em Lisboa. Luísa Batalha e Guilherme Cardoso ${ }^{4}$ identificaram nesse sítio dois fragmentos com "grafitos junto ao bordo" que, segundo eles, serviram para a "medida de líquidos". Se considerada a forma desses pequenos recipientes, que parece ter sido projetada de modo a facilitar a retirada e transferência de conteúdos, somada à presença das medidas de capacidade, parece claro que eles foram utilizados como medidores na comercialização de gêneros.

\footnotetext{
$4 \quad$ Batalha, Cardoso 2013.
} 

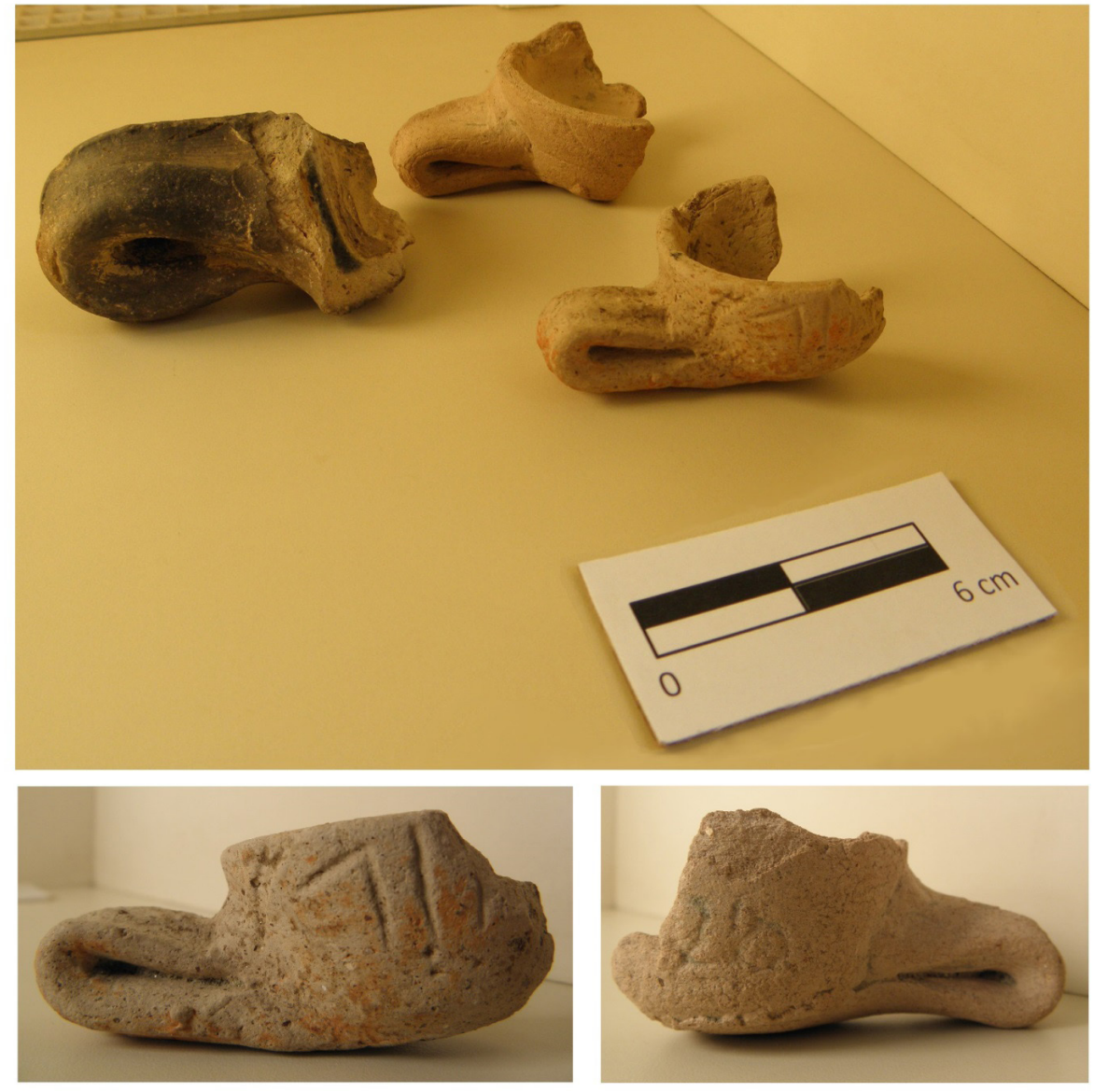

Figura 3: Medidores

Desenho Foto: Marcos André Torres de Souza. 


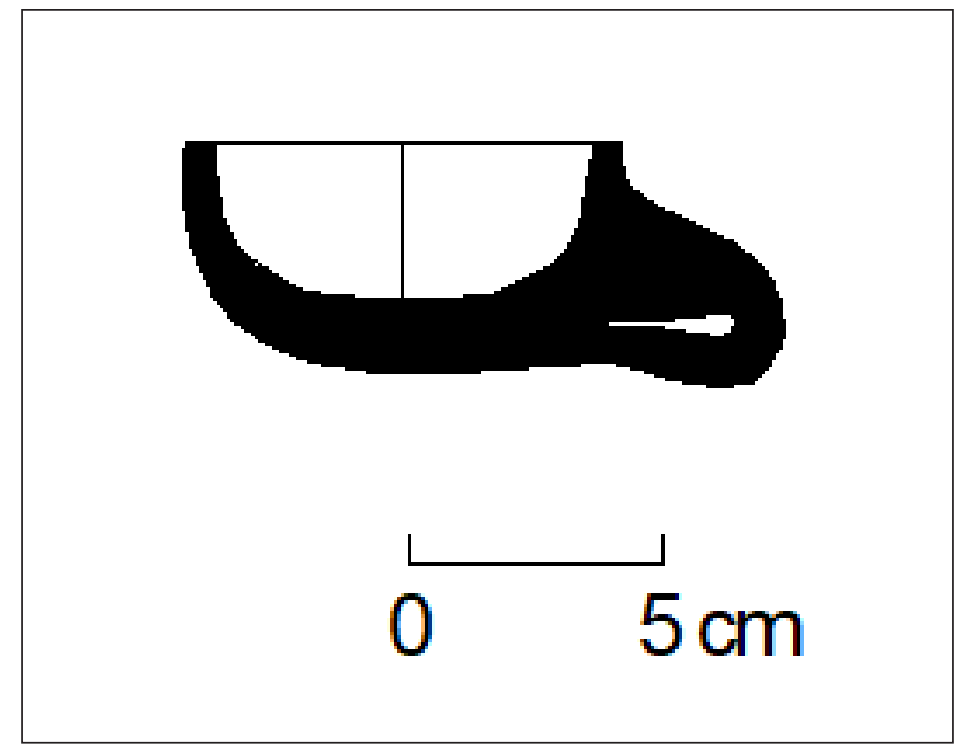

Figura 4: Exemplo de medidor

Desenho: Marcos André Torres de Souza.

Na primeira metade do século XVIII, o Rio de Janeiro era uma florescente cidade comercial. Após a descoberta de ouro nos sertões do Brasil e o afluxo de livres e cativos para o trabalho nas Minas Gerais, ele asumiu um importante papel na vida na colônia. Ponto de chegada e partida de pessoas, bem como ativo entreposto comercial, funcionava como ligação entre Portugal e as vilas e arraiais mineradores. É nesse contexto que se inserem as cerâmicas encontradas na amostra, embora seja difícil precisar a escala de comercialização desses ítens.

Um fragmento, entretanto, cuja forma e decoração são únicas na amostra (Figura 5), dá uma pista sobre a possível relação dos estabelecimentos existentes nas proximidades do sítio com viajantes e o comércio de longa distância. Embora únicas, essa forma e essa decoração estão entre as mais populares em algumas regiões mineradoras do interior ${ }^{5}$. Apesar de se tratar de evidência bastante discreta, esse fragmento permite considerar a possibilidade de que esse recipiente tenha sido trazido de lá por algum viajante. 


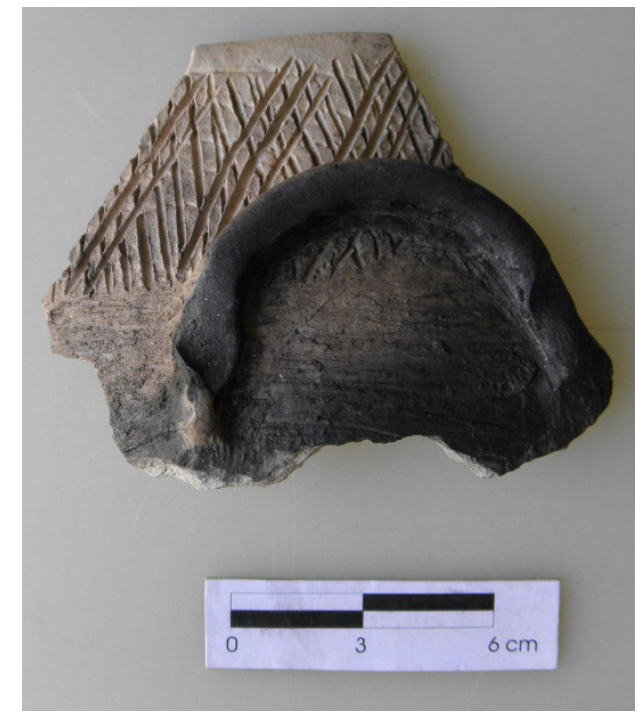

Figura 5: Fragmento cerâmico com decoração incisa sobreposta a roletes aparentes Desenho Foto: Marcos André Torres de Souza.

Somam-se às cerâmicas já descritas, conjuntos que remetem a referenciais portugueses. Embora os estudos sobre a cerâmica simples do Brasil colonial sejam ainda incipientes, merece ser destacada essa possível influência. Nos recipientes empregados no preparo de alimentos, há pelo menos duas formas de panela que, no nosso entendimento, se aproximam das formas portuguesas do período, descritas na literatura. A primeira é um tipo de vasilhame bastante grosseiro, com queima oxidante-redutora, antiplástico mineral pouco homogêneo e manufatura por modelagem (Figura 6a). Consultando os trabalhos resultantes de pesquisas feitas em Portugal, estamos encontrando formas semelhantes a essa, provenientes de contextos pós-medievais ${ }^{6}$. Um dado interessante nesse tipo de forma diz respeito às suas asas, que são vasadas, assemelhando-se às dos recipientes portugueses ${ }^{7}$. Convém notar que esse tipo de pegador não era comum no Brasil, onde ele era inteiramente preso ao corpo da peça.

\footnotetext{
6 Cf. Cardoso, Rodrigues 2002; Diogo, Trindade 2000; Silva 2012.

7 Cf. Diogo, Trindade 1995.
} 


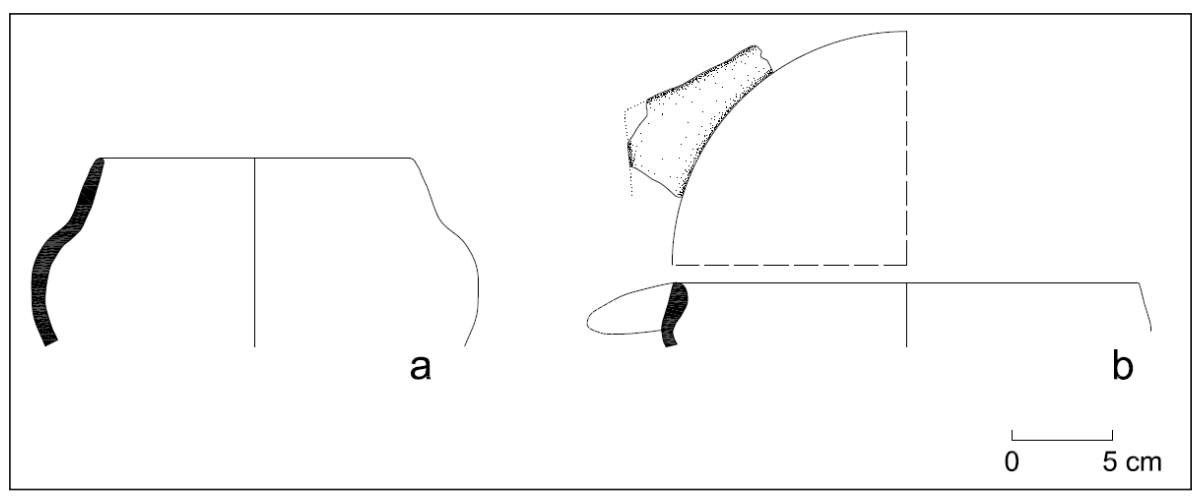

Figura 6: Formas de recipientes usados no preparo de alimentos Desenho: Marcos André Torres de Souza.

Um outro tipo de forma caracteriza recipientes de manufatura um pouco mais elaborada. São panelas de paredes finas, capacidade baixa e antiplásticos mais homogêneos. Assim como no caso anterior, encontramos semelhanças entre elas e algumas formas portuguesas do período ${ }^{8}$. Outras evidências mais discretas sugerem também a penetração de referenciais portugueses, como é o caso de um tipo de pegador de formato triangular que era colocado na borda do recipiente. Igualmente incomum em contextos brasileiros, foi descrito em Portugal por Fernandes e Carvalho ${ }^{9}$, associado a frigideiras (Figura 6b).

Para além dos recipientes usados no preparo de alimentos, encontramos influências que nos sugerem, igualmente, a adoção de referenciais portugueses. É patente na amostra uma incidência muito baixa de itens ligados ao serviço e consumo de alimentos - malgas e tigelas - que compreende apenas $4,8 \%$ da amostra. Para esses dois tipos de recipientes, consideramos aqui a diferenciação feita por Peixoto e Lima (neste volume). Segundo as autoras, as malgas são recipientes de forma aberta, corpo mais hemisférico, bordo boleado, ligeiramente extrovertido e com pé anelar tendencialmente alto. Já as tigelas têm forma aberta, corpo cilíndrico mediano, bordo boleado, fundo plano e pé anelar com diâmetro ligeiramente menor que a abertura da peça. Segundo essas autoras, ambas eram utilizadas de maneira individual à mesa, no consumo de alimentos, ainda que as tigelas maiores pudessem ser usadas também para o serviço de alimentos.

Tendo em vista que elas se mostraram muito reduzidas quantitativamente, não foi possível verificar com segurança as técnicas empregadas

\footnotetext{
8 Cf. Silva, Guinote 1998.

9 Fernandes, Carvalho 1998; ver também Gaspar, Gomes 2012.
} 
na sua confecção ou preferências específicas no uso de temperos. No que diz respeito à queima, ela parece se assemelhar à dos recipientes usados na estocagem de alimentos. Ao contrário dos demais conjuntos, essas peças não apresentaram asas ou alças. A baixa densidade desse conjunto faz supor que, para essa função, outras categorias materiais estavam sendo utilizadas, como as faianças portuguesas e as porcelanas, o que em certa medida reforça a pujança crescente da economia do Rio de Janeiro e sua conexão com Portugal e outros centros europeus.

As poucas tigelas e malgas de cerâmica identificadas sugerem a adoção de elementos estéticos apreciados pelos portugueses no período, como a presença de frisos próximos à borda (Figuras 7 e 8), bastante representados na literatura referente ao período pós-medieval em Portugal ${ }^{10}$.

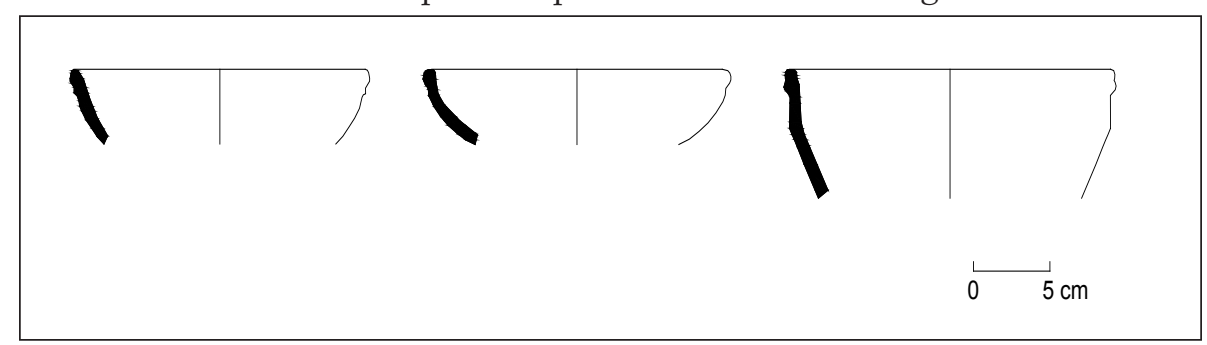

Figura 7: Recipientes utilizados no consumo de alimentos

Desenho: Marcos André Torres de Souza.

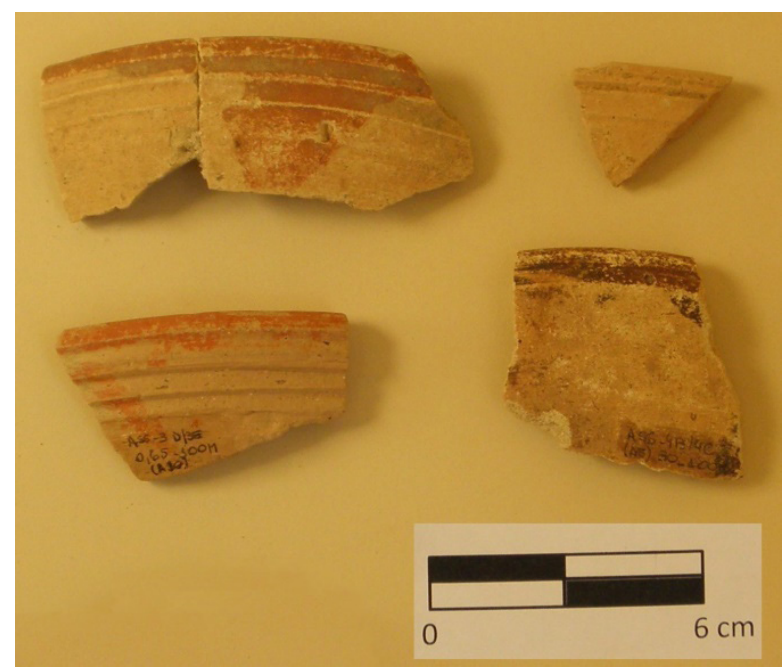

Figura 8: Recipientes usados no consumo de alimentos

Desenho Foto: Marcos André Torres de Souza.

10 Silva, Guinote 1998; Diogo, Trindade 2000. 
Ao considerarmos os itens utilizados no serviço e consumo de alimentos, é importante levar em conta a preferência dos cativos por tigelas e malgas. Em outros contextos arqueológicos com a presença de comunidades escravizadas no Brasil, esses itens estão quase que invariavelmente presentes e em números relativamente expressivos ${ }^{11}$. Contudo, esse tipo de forma está praticamente ausente na amostra da Rua da Assembleia. Quando presentes, eles associam-se, do ponto de vista decorativo, a uma estética portuguesa.

Encontramos ainda alguns recipientes com um tipo de decoração que aparece descrita por autores portugueses como "barroca", entre eles Ferreira ${ }^{12}$, que explana de forma mais detida esse tipo de decoração. As peças "barrocas" encontradas na Rua da Assembleia possuem uma decoração composta pela combinação de acanalados e faixas formadas por apliques (Figura 9). Em amostras do Rio de Janeiro datadas do século XIX, esse tipo de decoração parece ter sido mais popular, aparecendo, inclusive, nas ilustrações feitas por artistas europeus que passaram pela cidade no período. Esse foi o caso de Jean-Baptiste Debret, que visitou a cidade na primeira metade do século XIX e representou alguns recipientes cerâmicos usados à época ${ }^{13}$. Tal caso é interessante na medida em que, em Portugal, esse tipo de decoração aparece geralmente descrito em contextos mais antigos ${ }^{14}$.

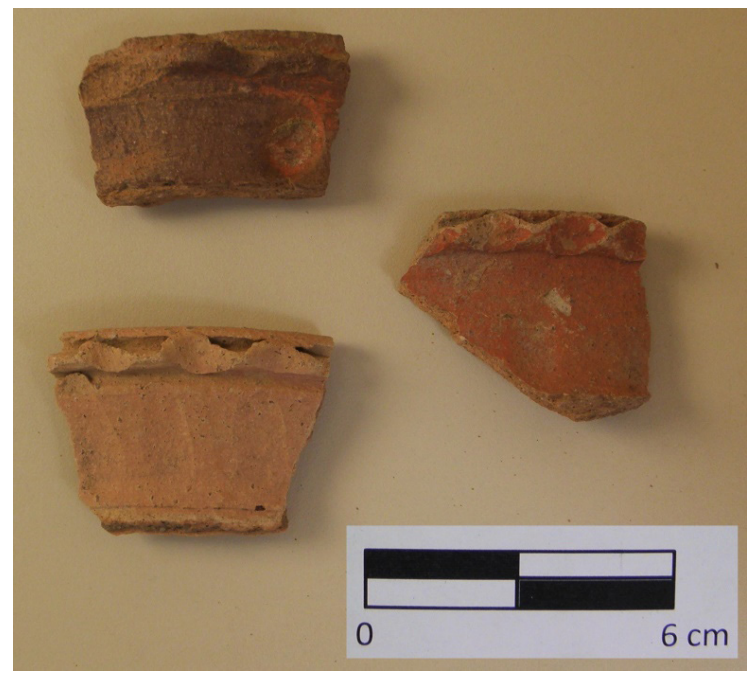

Figura 9: Peça com decoração barroca

Desenho Foto: Marcos André Torres de Souza.

\footnotetext{
$11 \quad$ Symanski, Souza 2007.

12 Ferreira 1995.

13 Bandeira et al. 2007.

14 Ferreira 1995.
} 
A presença conspícua de elementos formais e decorativos portugueses na cerâmica encontrada no sítio, cobrindo diferentes categorias funcionais, é um caso que exige atenção, sobretudo se levarmos em conta outros contextos brasileiros, onde eles aparecem de forma mais discreta e mais profundamente transformados. Ao que as circunstâncias parecem indicar, a influência lusitana tendia a se fazer mais presente nos centros urbanos mais movimentados e com conexões mais estreitas com a metrópole, onde o trânsito, a presença e a atuação de portugueses eram mais marcantes.

A penetração desses referenciais em espaços como as cozinhas, onde tradicionalmente as influências africanas tendiam a ser mais acentuadas, pode ser considerada uma evidência de que o sistema alimentar da cidade estava sob o controle mais direto da população livre eurodescendente, que se sentia mais identificada com os gostos e preferências de Portugal.

Nesse cenário, é digna de nota a pouca influência indígena na cerâmica analisada. Embora pesquisas arqueológicas em andamento mostrem-se bastante promissoras no que diz respeito à identificação de referenciais seus nas práticas materiais da cidade nos seus primeiros momentos, foram parcas as evidências encontradas na amostra que remetessem aos nativos. Entre essas, a que pode ser relacionada com segurança a esses grupos é a decoração corrugada, que era produzida por pressões regulares dos dedos, em sentido perpendicular ou transversal à peça, dando origem a um aspecto rugoso na sua superfície externa. Claramente associada aos indígenas, constitui-se em um dos poucos indicadores seguros de uma influência desses grupos na cerâmica.

\section{Considerações finais}

Em uma análise preliminar, o conjunto do material cerâmico encontrado sugere que, no Rio de Janeiro setecentista, o aparato material ligado às práticas alimentares esteve sujeito a influências culturais concorrentes. Os dados aqui considerados apontam para uma situação de encontros e negociações culturais bastante complexas, que tiveram como resultado expressões híbridas, características de um universo multicultural. Embora o texto aqui apresentado represente apenas uma primeira aproximação em relação a essas trocas, é possível vislumbrar um cenário no qual as expressões materiais da vida na cidade, no começo dos setecentos, permitiram o estabelecimento de diferenças, bem como a criação de referenciais para a coexistência de pessoas muito diferentes entre si. Esta reflexão é, no nosso entendimento, promissora, e deve ser explorada em maior profundidade na apresentação dos resultados finais deste estudo.

Pouco tempo depois do solo arqueológico que continha esses artefatos cerâmicos ter sido selado pelas edificações erigidas na segunda metade do século XVIII, a cidade tornou-se a nova capital da colônia e sua crescente 
importância econômica alinhou-se a uma nova vocação, de caráter político-administrativo. Preservou-se nesse solo um conjunto de evidências contundentes, que nos permitem flagrar a emergência de práticas culturais híbridas e inteiramente novas, ligadas ao chamado "cadinho racial brasileiro" - um dos mais debatidos fenômenos da história social no Brasil.

\section{REFERENCIAS}

Agostini, C. (2010), "Panelas e paneleiras de São Sebastião: um núcleo produtor e a dinâmica social e simbólica de sua produção nos séculos XIX e XX", Vestígios 4: 127-144.

Bandeira, J., Debret, J. B., Lago, P. C. (2007), Debret e o Brasil: obra completa (1816-1831), Capivara, Rio de Janeiro.

Batalha, L., Cardoso, G. (2013), "Poço seiscentista no Vale de Alcântara (Santa Isabel, Lisboa)", Emérita 1: 113-140.

Cardoso, G., Rodrigues, S. (2002), "Conjunto de peças de cerâmica do século XVII do convento de Na. Sra. da Piedade de Cascais", in Actas do 3. ${ }^{\circ}$ Encontro Nacional de Arqueologia Urbana, Almada, Câmara Municipal de Almada, 269-288.

Cavalcanti, N. O. (2005), "O comércio de escravos novos no Rio de Janeiro setescentista", in M. Florentino (org.), Tráfico, cativeiro e liberdade: Rio de Janeiro, séculos XVIII$X I X$, Civilização Brasileira, Rio de Janeiro, 15-77.

Chmyz, I. (1976), "Terminologia arqueológica brasileira para a cerâmica”, Cadernos de Arqueologia 1.1: 119-148.

Diogo, A. M. D., Trindade, L. (1995), Cerâmicas de Lisboa provenientes de contextos datados. Materiais de uma lareira de cozinha destruída no terremoto de 1755 , in Actas das 1.as Jornadas de Cerâmica Medieval e Pós-Medieval: métodos e resultados para o seu estudo, Câmara Municipal de Tondela, Tondela, 163-170.

Diogo, A. M. D., Trindade, L. (2000), Cerâmicas de barro vermelho, encontradas em entulhos do terramoto de 1531, na intervenção arqueológica da Rua dos Correeiros, Lisboa, Revista Portuguesa de Arqueologia 3.2: 201-235.

Fernandes, I. C. F., Carvalho, A. R. (1998), Conjuntos cerâmicos pós-medievais de Palmela, in Actas das 2.as Jornadas de Cerâmica Medieval e Pós-Medieval: métodos e resultados para o seu estudo, Câmara Municipal de Tondela, Tondela, 211-256.

Ferreira, M. A. (1995), "O Barroco na cerâmica doméstica portuguesa", in Actas das 1. as Jornadas de Cerâmica Medieval e Pós-Medieval: métodos e resultados para o seu estudo, Câmara Municipal de Tondela, Tondela, 151-162.

Gaspar, A., Gomes, A. (2012), "A cerâmica moderna do Castelo de São Jorge: produção local de cerâmica comum, pintada a branco, moldada e vidrada e de faiança", in A. Teixeira, J. A. Bettencourt (eds.), Velhos e Novos Mundos. Estudos de Arqueologia Moderna, Centro de História de Além-Mar, Lisboa, 719-732.

Mott, L. R. B. (1976), "Subsídios à história do pequeno comércio no Brasil”, Revista de História 53.105: 81-106. 
Silva, R. C. (2012), "Primeira abordagem a um depósito moderno no antigo paço episcopal de Coimbra (Museu Nacional de Machado de Castro): a cerâmica desde meados do século XV à consolidação da renascença”, in A. Teixeira, J. A. Bettencourt (eds.), Velhos e Novos Mundos. Estudos de Arqueologia Moderna, Centro de História de Além-Mar, Lisboa, 977-890.

Silva, R. B., Guinote, P. (1998), O Quotidiano na Lisboa dos descobrimentos. Roteiro arqueológico e documental dos espaços e objectos, Comissão Nacional para as Comemorações dos Descobrimentos Portugueses, Lisboa.

Souza,M.A.T.(2015),"When all bases are flat: Central Africans and situated practices in the eighteenth-century Brazil”, in P. P. Funari, C. E. Orser Jr. (eds.), Current Perspectives on the Archaeology of African Slavery in Latin America, Springer, New York, 77-97.

Symanski, L. C. P., Souza, M. A. T. (2007), O registro arqueológico dos grupos escravos: questões de visibilidade e preservação, Revista do Patrimônio Histórico e Artístico Nacional 33: 215-243. 